Masri, M. \$.. Lundin, R. E., Page, J. R., and Garcia, V. C., Tature, 215, 753 $(196 \pi)$.

3 Mogan, (G. X.. Fed. Proc., 27, 932 (1968).

${ }^{4}$ Rodricks, J. Y., J. Amer. Oil Chem. Soc., 46, 149 (1969).

- Briggs, H. M. and Gallup, W. D., J. Animal Sci., 8, 479 (1949).

'Weil, C. S., Biometrics, 8, 249 (1952).

'Newbern", I. II., and Butler, W. H., Cancer Res., 29, 236 (1969).

\section{Vertebrate Fauna from the Lower Trias of Australia}

Australra's lack of abundant Permian and Triassic tetrapod rertebrate fauna has long been an exigma to palaemtongists. Both labyrinthodont and reptilian remains are common in South America, Southern Africa and Madagascar, and fairly common in India, while part of a labyrinthodont mandible has recently been reported from Aitarctica ${ }^{1}$. Apart from a recent find in Western Australia, and a small collection from Tasmania, the few described Australian labyrinthodonts have been isolated specimens, while a single individual from Tasmania is the only Australian pre-Jurassic reptile.

In 1965 Alan Bartholomai, following up a report of bone in the previously barren Upper Rewan (Lower Trias) red beds south of Rolleston in Central Queensland, found scattered labyrinthodont and thecodont reptilian remains. He added to the collection in 1966 and 1968 , and in September 1969 was joined in the field by Alex Ritchie and Kingsley Gregg from the Australian Museum, and by Anne Howie. Most of the remains were found as isolated bone fragments which had weathered out from the Rewan's banded red and lime green mudstone, a small proportion occurred in rare sandstone layers, while the smaller specimens tended to be preserved in purple ferruginous nodules.

Although the greater part of the collection consists of labyrinthodont remains (Fig. 1), it also contains dipnoan tooth plates, a small quantity of thecodont material and some twelve small skulls of the earliest known Australian reptiles. Dissociated remains of at least thirty labyrin. thodonts were recoverod and four partial skulls were found in association with postcranial material. The most common species is a small parotosaur while a second species has a broad skull with large, laterally placed orbits in the anterior half of the skull roof and prominent tabular horns. Apparently associated with this second skull type are poorly ossified neorhachitomous vertebrae. These specimens are being prepared in Sydney by Anne Howie, who will publish a full description later.

Alan Bartholomai is describing the small reptiles, all of which are preserved in acid resistant nodules and thus present considerable problems of preparation. They appear on initial investigation to be two or three species of lepidosaurian reptile and are provisionally allied with the Paliguanidae (Fig. 2), or short skulled eosuchians, other members of which have been described from South Africa ${ }^{2,3}$ and Central Asia ${ }^{4}$. It seems that, apart from the glaring absence (so far) of any trace of the Synapsida, a vertebrate fauna similar to that found in other southern continents did exist in the Lower Trias of Australia, and it

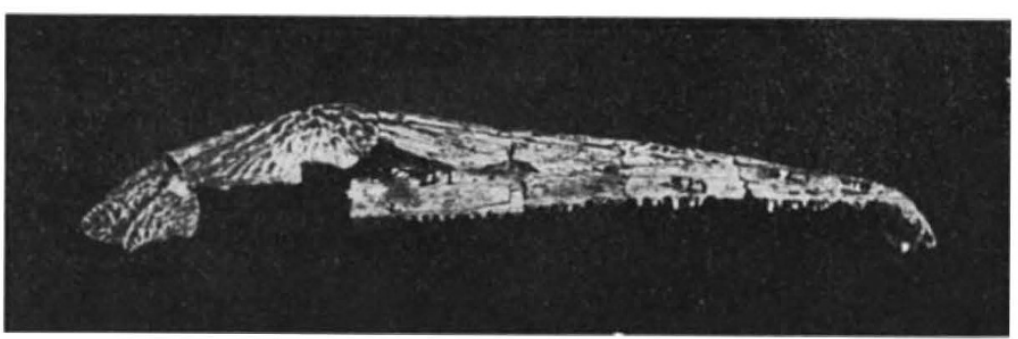

Fig. 1. Left ramus of the lower jaw of a labyrinthodont from the Rewan seen in lateral view $(\times 4 / 5)$.

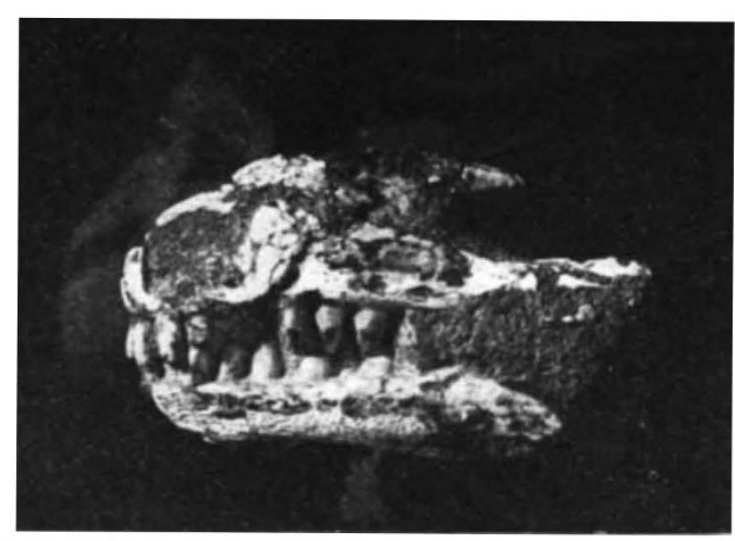

Fig. 2. Left lateral view of the front end of the skull of one of the small "Paliguanid reptiles $(\times 2)$.

is to be expected that a further search will produce more material.

The Queensland Museum, Brisbane.

Alan Bartholomai

School of Biological Sciences,

ANNE HowIE

University of Sydney.

Received Norember 28,1969

${ }^{1}$ Barrett, P. J., Baillie, R. J., and Colbert, E. H., Science, 161, 460 (1968).

2 Broom, R., Rec. Albany Mus., 1, 1 (1903).

${ }^{3}$ Broom, R., Proc. Zool. Soc., 487 (1926).

${ }^{4}$ Koh, T. P., Bull. Geol. Soc. China, 20, 73 (1940).

\section{Sperm Transfer by Spermatophores in Glossina austeni Newstead}

Spermatophores have apparently never been reported from higher flies. Davies ${ }^{1}$ named three nematocerous families that have spermatophores, and more recentlyDownes $^{2}$ added a probable fourth to the list. Here I describe the spermatophore of Glossina austeni (Muscidae, Cyclorrhapha), and briefly discuss the implications of the discovery for current experimental techniques of studying Glossina reproduction.

Female flies were 2-4 days old when used for the mating studies, and males were at least 10 days old; observations were made at $25^{\circ} \mathrm{C}$. To obtain mated flies, virgin pairs were left undisturbed in glass tubes for $24 \mathrm{~h}$.

The spermatophore is a prominent colourless object in the uterus of recently mated females (Fig. 1). A typical example measured $700 \times 500 \times 400 \mu \mathrm{m}$, but the size varies. By microscopical examination of fresh and fixed specimens, a single closely packed sperm mass is easily seen inside the transparent body of the spermato. phore; the mass can be dissected out whole from the surrounding material even when fresh. When viewed through the microscope, sperm are active in spermatophores placed in saline solution. The part of the spermatophore in immediate contact with the rounded sperm mass appears more trans. parent than remoter parts and is firmer in consistency. It keeps its shape even after the sperm mass is dissected out, but breaks casily on compression. As shown in Fig. 1, the spermatophore and the sperm mass are visible through the uterus wall.

Spermatophores are found adhering to the antero-dorsal wall of the uterus, and project backwards into the uterine cavity to an extent depending on spermatophore size. At this point on the wall is the opening of the fused spermathecal ducts. 